\title{
Cinema para o Estudante de Medicina: um Recurso Afetivo/Efetivo na Educação Humanística
}

\author{
Movies for Medical Students: An Effective \\ and Affective Resource in Humanistic \\ Medical Education
}

Pablo Conzálč Blasco

Dante .M. C.. Gallian²

Adriana F. T. Roncoletta ${ }^{3}$

Grazjcla :Morcto

PAIAVRASCHAIE

Cinenia;

- Matcrizis dic Tinsino;

Educaçàn Mćdica:

- Medicina de Famíliá.

KH:XW(.)RDS

- Cinema;

- Teaching Marcrials:

- Education, Medical;

- Family Practice.

ercbido em: 17/02/2004

Reencaluinhado crn: 07/05/2004

Reencaminhado crn: 02/12/2004

Arovado em: 25/02/2005

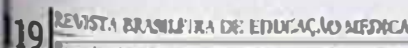

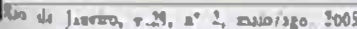

\section{RESUMO}

O bumanismo \& parte da formagão do médico para construir-sc como um profissional capaz de entender e cuidar do scus pacicntes. As humanidades as astes sảo recursos cducacionais para promover o hurmanismo nos futuros médices. O cinema es particularmente útil para educar a afetividade do estudante. Educar as ernoçoes requer estmalgyjas inovadoras modernas que väo ao encontro das necessidades do estudante. O processo vai alem do ensino teórico de atitudes para, utilizando a cultura da emoçso e da imagem na qual o estudante esta imerso, promover a reficxão vital. A abordagcn metodológica trabalha as emoșises do estudante como ponto de partida para, através de grupos de refleväe possibilitar a consitrugazo de conceitos na relacro médico-paciente e criar o hábilo da reflexéo habitual que pode ser iransportada para as atividades do colidiano. O objetivo deste aprendizado é promover no ruturo inédico o evercicio da relilexāo, base do compromisso vocacional profissional. A melodologia pode ser usada em varjos cemários de educaçơ médica, sempre que os professorcs terham fanviliaridade e gosto pelas humanidades e priorizem o aprondizado centrado no aluno.

\begin{abstract}
Humanism is a cribical trail for physicians 10 karn for cheveluping like profiessionals who are corsmithed 10 unckerstanding and caring for their patients. Humanities and arts are cducational resources that can be used to develop tuture physicians' humanism. Movie's arte a particularly uscful resource ior developing medical students affective donsin (i.e., altiludes and beliefs). Teaching in the affective domain requires innovative instructional stsatcgies that mect cur learmets' necels and with techniques that are current and fit the students' culture. These stratcgices must move beyond lecturing abesut theoretical concepts to using modalities that stir karners emotions, provite visual images, and promote thinking and retlection. The authors approach invokes learnes' cmotions, aids the construction of concepts through refection in groups, helps therm learn new wavs to strengthen physician/paticnt relationships and communicotion skills, and give's the'm a framervork to refket on and apply the'se impostant conxepts in their daity live's. This innovative learning process aims to encourage the futures physicians to become self. directed learmers and develop career commitments. This methodology can be used in se'veral edecalional sets for nxedical students and rcquires teachers who are iamiliar to humanities and to the student centered lcarning process.
\end{abstract}

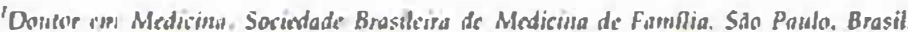

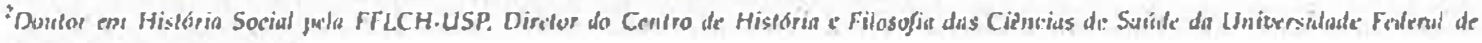
Silo Panulu. San Paulo. Brasit.

'Midica de Familia. Saciedade Brasileira de Miticina de Familin. Sdo Paulo. Brasil.

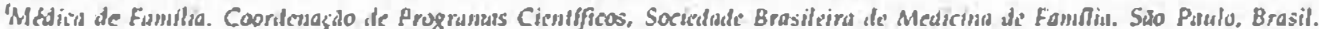




\section{MEDICINA E HUMANISMO}

$\Lambda$ verdadeira razĩo de ser da Medicina é o cuidado da pessoa doente. lista é a origem histórica c a essência da profissão médica. O médicu deve estar, pois, em função do paciente para cuidar dele com ciência c dedicação. Cuidar exige, cm primeirolugar, compreender, já que a comprecnsão do paciente é condição necessária prévia para dispensar os cuidados adequados. Comprcender o paciente significa compreender a pessoa, a doença c o significado que a enfermidade tem para o pacientc. A doença é para o cnfermo uma menteirı de estar m vida. quer dizer, uma forma de vida que tem sua linguagem própria c que devc encontrar no médico um receptor sensível, necessário à decodificação adequuada dos significados.

Estas consideraçōes puntuais nos colocam frentc à questão central: a necessidade que o médico tem de incorporar uma perspectiva antropológica da doença através da qual pode realmente compreender o paciente em seu adnecer. E, como o médico não se limita à especulação térícica de conccitos mas tem de vivê-los na prática, deverá ser a sua uma antropologia ativa, que permeie sua atuação clínica. Humanismo e Antropologia não sảo para o médico um simples apêndice cultural ou um complemento interessante na sua formação; sảo a dimensão necessária de quem pretende compreender e cuidar com cficácia, além de um recurso de conhecimento e de pussibilidades humanas por meio do qual constrói também a sua identidade como médico!

O humanismo é fonte de conhecimentos que o médico usa para sua profissão. Conhecimentos tão importantes - nem mais, nem menos - quanto os adquiridos por outros caminhos e que igualmente auxiliam no cuidado do ser humano enfermo. Percursos diferentes na aquisição do saber, que ellcontram na pessoa - terreno próprio do atuar médico - sua meta comum e propiciam, em mútua convivência, união de forças, sinergia na vontade de curar. Para Gregorio Mararión, a formação humanística é tarefa e compromisso essencial do médico, fonte de conhecionentos, recurso instrumental na sua profissão: "O humanismo, ambicioso e ao mesmo tempo humilde, serve para amadurecer, para firmar e fazer prudente e eficaz o instrumento da profissão"2.

A medicina ocidental, em sua origem, era uma ciência essencialmente humanística, assentando suas raízes c sistema tebrico no homem como ser dotado de corpo e espírito. $O$ médico era, antes de tudo, um filosofo: um conhecedor das leis da natureza e da alma humana. O progresso tecnolúgico e os avanços científico-positivos vicram, de algum modo, distrair o médico de suas verdadeiras raízes, onde se encontra o motivo e razão real de sua missão: o cuidado da pessoa enfferma. Oassim denominado processo desumanizante da medici- na - verdadeiro paradoxo conceitual - poderia resumir-se nesta atitude de esquecimento das raízes históricas da profissão médica. Acaba-se prestando maior atenção ao processo de investigação do conhecimento das doenças e aus recursus terapéuticos do que ao prüprio doente. $\wedge$ pesson do enfermo e sua identidade correm o risco de se perderem no meio de um labirinto tecnológico, cuja importância, por outro lado, ć incgável. $\Lambda$ re-humanização da medicina - quer dizer, a reconquista da postura humanistica do médico - é um desafio atual, um resgate das origens, onde o progresso deve ser incorporado e colocado a serviço do doente, que deve ser o protagonista do cenário médico. $\wedge s$ humanidades - ciências do homem - surgem neste contexto como recurso importante, que fará o médico lembrar-se na prática de sua verdadeira origem?

A proposta de resgate do humanismonão obedece a uma visão romântica da medicina, nem mesmo a uma estratígia de ação para trabalhar de modo mais humano questōes de ordem prática e de importância cvidente, como, por exemplo, a base de uma relação médico-paciente eficaz.. A perspectiva humanistica é uma imposiçăo de rigor científico, no âmbito episte. mológico. Dito com outras palavras: scm humanismo, a Medicina estaria amputando uma de suas fontes cientificas do saber. É preciso recuperar a perspectiva humanística da Medicina, pois o humanismo é inato à profissão médica. Um médico sem humanismo não será propriamente médico; na melhor das hipóteses, trabalhará como um "mecànico de pessoas"4.

Historicamente, até finais do século 19, a Medicina apresentava um cquilibrio harmonioso entre as duas facetas inseparáveis que compōem a sua atuação: a ciência e a arte. Razōes de ordem cultural na formação dos médicos, um progresso técnico mais vagaroso, um estilo e ritmo de vida onde a reflexão humanista fazia parte do quotidiano dos médicos podem explicar esse equilíbrio histórico. Em qualquer caso, é evidente que se requeria do médico um crescimento paralelo em ambos os setores - o técnicu c o humanístico - para alcançar uma formação equilibrada, completa. l'arece lógico pensar que, quando os avanços cientificos se sucedem $\mathrm{cm}$ ritmo vertiginoso, para manter este equilibrio é necessiriria uma ampliação do àmbito do humanismo, quer dizer, um humanismo à altura do avanço técnico. Talvezz seja desta ampliação do humanismo, adaptada aus dias de hoje, em linguagem atual, que carcce o processo de educação médica. Cai-se, assim, numa desproporção que se reflete em profissionais formados tecnicamente, com sérias deficiências humanas. Profissionais disformes, com hipertrofias, sem equilibrio, que naturalmente não conquistam a confiança do paciente que espera um médico equilibrado. 
É missão da universidade c compromisso dos envolvidos no processo da formaçào médica ampliar o conceito hunanista em moldes modernos, abrindo horizontes e novas perspectivas. A universidade, representativa do progresso, tem de sc esforçar por at:ngir um novo e moderno equilíbrio das duas facetas da medicina, técnica e arte. E, para isso é preciso metodologia, sistemítica, para reaprender a fazer as coisas quando estas são muitas e comandadas por um progresso científico que avança a cada scgundo. É também missão da universidade recuperar o humanismo, sem impedir, de modo algum, a aplicação da ciência aos problemas da docnça, mas, pelo contrário, fortalecendo-a em sua esfera apropriada e sobre bases mais amplas que as atuais. Humanizar o ensino médico requer uma avaliação do processo de ensino, para procurar um aprendizado técnico c humano, equilibrado c simultàneos.

\section{AS HUMANIDADES E A EDUCAÇĀO MÉdICA}

O uso das humanidades na educação dos médicos constitui um recurso importante para a construção deste equilíbrio. Quando incorporado no processo de formação acadêmica, permite desenvolver a dimensão humana do profissional, vertente imprescind:vel no relacionamento com o paciente. $\dot{\mathrm{E}}$ justamente a dimensão humana do médico que o paciente sabc avaliar mellor e sobre a qual faz convergir suas solicitaç̉̄es. Calman' faz notar que o paciente quer um médico cducado, alguém que nło possua apenas conlıccimentos, métodos clínicos c expcriència, mas que também scja capaz de apreciar cada paciente como um ser humano que tem sentimentos e descjos; alguém que possa entendê-lo c ajudá-lo, explicando-lhe sua doença e amparando-o no sofrimento. Para saber lidar com estas realidades, as humanidades ajudam c, sobretudo, cducam. F.ducação é mais do que simples treino: implica uma atitude reflexiva no médico c um descjo contínuo de aprendizado ao longo de sua carreira profissional.

Atendendo a esta necessidade que procura caminhos para o moderno equilíbrio humanista, vêm emergindo linhas de pesquisa que integram as humanidades na formação dos estudantes de Medicina, mostrando que a arte facilita a compreensão das emoçīes humanas $c$ das atitudes do paciente perante a doença, ajudando o médico a cuidar do paciente corretamente7. A incorporaçāo das humanidades na educaçāo médica tem como objetivo educacional primordial despertar atitudes e valores, mutas vezes inesperados nos próprios estudantes, que estarão em função da escala de valores, da educação e da maturidade que cada um possua. Os objetivos não sc medem tanto pelos resultados finais como pela capacidade de comprecnsão ampliada sobre o ser humano que o processo lhes traz, incluido o que se denomina resultados latentes. Na verdade, este processo educacional através das humanidades sc assemella a uma viagem: importa mais o que se aprende durante o tempo que leva do que propriamente o destino. Um processo que atenta mais para uma educação real, e não para o simples treino ${ }^{8}$.

Não existe nestas iniciativas nada que possa ser interpretado como artificial ou mesmo como diletantismo, já que os próprios estudantes acusam falhas $\mathrm{cm}$ seu processo de formaçāo, mostrando-se particularmente receptivos a projetos desta índole. Um estudo interessante" analisaa percepção dos estudantes de Medicina em relação às deficiências em sua formaçāo humana. Aponta dois motivos para a carência de humanismo na educação dos futuros médicos: por um lado, o fato de o currículo médico estar, de ordinário, absolutamente preenchido e saturado de novas técnicas e conlecimentos, sem deixar espaço para discutir questōes de caráter humanistico; por outro lado, é muito mais fácil ensinarconlecimentos técnicos do que promover mudanças de atitudes de vida e de valores, quc seria o objctivo da formação humanística.

Criar o hábito de pensar e mostrar um caminho para a reflexão permanente são objetivos comuns de todas estas iniciativas humanísticas no processo de educạ̧ão médica. Uma preocupação presente entre os educadores, que tem cada vez mais espaço nas publicaçōes orientadas para a formação dos médicos.

Os recursos humanísticos na educação médica possucm o amplo espectro da condição humana. Cada vez com maior freqüêencia, surgem iniciativas vinculadas às humanidades $c$ às artes, na tentativa - urgente, c ao mesmo tempo, paciente e continuada - de conduzir o estudante de hoje, médico de amanlıã, ao caminho da reflexão sobre a riqueza da dimensão humana. Assim, cursos curriculares, obrigatórios ou eletivos, são oferecidos nas escolas médicas, alguns com experiência de anos e convenientemente institucionalizatos, outros ainda em caráter pioneiro. Literatura c teatro ${ }^{10.11}$, poesia ${ }^{12}$, ópera ${ }^{13} \mathrm{e}$ artes $^{14}$ compōem o mosaico de recursos que os educadores, em atitude verdadeiramente humanista, tomam emprestados das humanidades na tentativa de auxiliar na construção da identidade do futuro médico. O cinema tambérn vai fazendo sua aparição na literatura como um recurso humanístico possivel na educação médica ${ }^{15,16}$

\section{O UNIVERSO DO ESTUDANTE: UMA CULTURA DA EMOÇÃO E DA IMAGEM}

$\Lambda$ dimensão afetiva - cducação das emoçỉes - apresenta importância particular no processo formativo. As emoçōes do aluno nāo podem ser ignoradas neste processo. O educa- 
dor deve contemplá-las e utilizá-las pur se tratar de elemento considerado : undamental na perspectiva do educando, alem de ser uma porta de entrada para compreender o universo do estudante.

Nos aprendizados da vida - adverte Ruiz, Reteguil' -, muitas das coisas mais importantes não se transmitem por argumentaçāo, através do raciocínio lógico especulativo. Estes outros caminhes tèm a ver com o amor que se coloque no processu de educar e com a conseqüiente educação da aletividade. Com perspectiva histórica, o autor faz nutar como o culto à estética surge, nos dias de hoje, desvinculado dos valores próprios do ser - transcendentais, em linguagyem filoscifica - aos quais sempre esteve atrclado: nos clássicos, o belo une-se ao bom, ao verdadeiro. Surge a duvida - que cerlamente acomete muitos educadores - do possivel risco que supōe educar apenas a sensibilidade, ancorar-se na estética e nas emoçōes, sendo que os outros valores - o bom, o verdadeiro - permanccem conceitos estranhos, pouco definidos para o universitário de hoje. Não seria esta uma educação ficlícia, superficial, epidérmica, que nāo atingiria o núcleo do educando para promover atitudes duradouras e maduras?

Seguindo o raciocínio desse autor, podemos esclarecer que a educação através da estética, que atinge as cmoçōes c a sensibilidade, não é uma tentativa de ancorar na cmotividade os valores e atitudes que o estudante deveria incorporar. Trata-se de suscit.ur uma reflexão sobre estes valores catiludes. possivel incorporar um conhecimento técnico ou mesmo treinar uma habilidade sem refletir sobre cles; mas è impossivel adquirir valores, progredir em virtudes, incorporar atitudes, sem um prévio processo de reflexão. É justamente desencadear este processo de reflexảo, mediante recursos próximos ao estudante, o que se pretende com a estética, da qual o aprendizado através do cinema faz parte. Dito de outro modo: estabelecer um ponto de partida para uma atitude reflexiva, pista de decolagem para futuress aprendizados, seıssibilizaçāo para ensinamentos posteriores, que virão através de conteúdos específicos e, na maior parte das vezes, personalizados no exemplo.

Em culturas como as da Grécia Antiga, do Medievo ou a Renascentista, onde o pensamento c a ação moral sc estruturam de acordo com o esquema denominado clássico, o meio

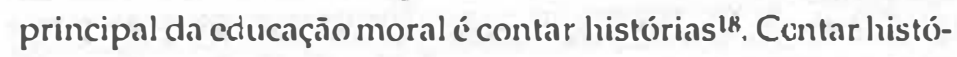
rias seria o substitutivo lógico para a impossibilidade de todos os homens se submeterem às experiências intensas de situaçōes humanas. ^ssim, as artes que contam histórias - teatro, literatura, ópera, cinema - teriam o papel de suprir as experiencias que nem todos podem vivenciar. i: deste modo que se pode produzir o que Aristóteles denominava calarse (purifi- (üı̇̃u), caminho obrigatório no pensamento grego pa:a chegar ao reconhecimento do belo, do pulchrum. Sem dúvida, o mais catártico é a realidade vivida; mas as histórias de vida, quando bem colocadas, têm um importante papel. Quer diz.er: não é função da arte "contadora de histórias" ou narrativa o simples divertir ou passatempo; mas, sim, provocar sentimentos - alegria, entusiasmo, aprovaçăo, reclaço, condenação-que configuram o "coração das gentes". Estc era c papel da tragédia grega. Estass histórias, as tragédias, provocavam a calnrse, que se pode entender num duplosentido. O primeiro, imediato, é a liberaçāo dos sentimentos, como uma limpeza orgànica, como um purgnnte. O segumclu, unuito impo:tante, ¿ que mediante a catarse "colocam-se no seu lugar" todos estes sentimentos acumulados - emuçōes - que nāo poucas vezes se armazenam de modo desordenadoir.

Eis uma importante consideração que nos faz progredir em nossa reflexão sobre o universo afetivo do estudante. Partimos da premissa de que as emoçées devem ser contempladas no processo educacional, sendo insensatez ignorá-las. Neste ponto, os comentários dos estudiosos em antropologia, amparados nos cnsinamentos dos clássicos, nos mostram que nảo basta contemplar as emoçōes, mas que é preciso utilizá-las, dar vazån a clas, para que deste modo posisam ir sc colocando no seu lugar. P’ermitir no espaço acadêmico o fluir das emoçōes - através da discussão, de partillıar os sentimentos - abre caminhos para uma verdadeira reconstruģão da afetividade.

Ferrés apresenta um estudo recente que constitui obra de consulta essencial para a questão que nos ocupa ${ }^{19}$. Trata-se de uma notável análisc suciológica do tema, que descreve as caracteristicas da cultura do estudante - também do universitário - nos dias de hoje. Compreender a cultura e o universo onde o estudantc está inscrido ć condiçāo prévia necessária ao sucesso de qualquer projeto educacional.

$\mathrm{O}$ jovem estudante cliega às màos do educador inserido numa formaçāc) que privilegia a informação rápida, o impacto emotivo, a intuiçāo, em detrimento do raciocinio linear, lógico e especulativo. É uma característica que diz respcito não apenas à cducaçāo $\mathrm{c}$ ao aprendizado, mas à própria vida na qual está inserido: uma cultura da pressa, onde a reflexảo dificilmente tem vez. ^nota textualmente o autor: "as pessoas se refugiam na velocidadc, são impelidas ao presente, na็o conseguem pela prassa freqü̈entar o passado". Trata-se de um contexto cultural onde predomina o fragmentário, o rápido, o sensorial, que naturatmente se traduz em atitudes do imediato, dinâmicas, impacicntessaté.

Parece natural q̣uc neste universo seja a imagem sensorial, e não o conceito lógico que assuma a função de protagonis. 
ta. É o que o autor denomina "cultura do espetáculo", um contexto onde o sensorial, a imagem são potencializados por atingirem diretamente o espectador, provocando emoçōes sem passar previamente pelo processo de compreensão intelectual. Oespectador obtém uma recompensa afetiva imediata com a imagem. Na cultura da palavra e do conceito, que também atinge as emoçōes, torna-se necessária a passagem obrigatória prévia pelo processo racional para depois surgir a emoção. Com a imagem este caminho converte-se em atalho, e as cmoçōes são despertadas diretamente, sem necessidade de "pagar tributo prévio ao intelecto". Nącultura do conceito, é preciso compreender primeiro para se emocionar depols; na cultura da inagem, as emuegües derivam diretansente dos significantes - que são o veículo que carrega os conceitos, o visual que se apresenta - sem ter que se chegar previamente nos significados, no conteúdo conceitual.

A cultura do espetáculo privilegia uma representação do mundo concreta, dinâmica, sensitiva e emotiva. As respostas racionais representadas pelo "estou de acordo" ou "discordo" são substituidas por respostas cmotivas suscitadas pela imagem - "gosto" ou "nāo gosto" -, onde existe uma aceitação ou rejeiçāo visceral, de impacto, sem participação do racional. Com isto não se pretende, em absoluto, dispensar a necessidade do raciocinio para a construção dos conceitos no aprendiæado. Apenas se afirma que é preciso passar antes pelas emoçōes, porque ć assim, deste modo, que os estudantes estão habituados a proceder. $A$ emoção é porta de entrada para posteriores construçōes lógicas. Quem está acostumado a se guiar pelo sentimento, pela cmoção - provocada na maioria das vezes por imagens, externas ou internas - dificilmente aceitará raciocinios lógicos se a emoção nāo the facilitar o caminho.

Esta é a situação contextual onde a geração atual se situa. E dela temos que partir se queremos interagir satisfatoriamente no processo educacional. A cultura do espetáculo nos aponta uma linguagem na qual é possível estabelecer sintonia com o cducando. O educador tem, pois, de assumir uma postura que incorpore a emoção no processo educacional. Não basta contemplar as emoçōes, saber que elas existem c muito menos temê-las como elemento que pode sabotar o processo formativo. Torna-se necessário utiliz:-las, mesmo como uma vacina sábia, que garanta a saside do aprendizado. Deve-se chegar a uma postura conciliadora, permitindo que seja a emoção a que cumpra o papel que lhe cabc: ativar o descjo de aprender, motivar o estudante. Somente depois é possível, através da racionalidade, colocar os fundamentus conceituais.

Ferrés ${ }^{19}$ aponta que ć preciso superar o dualismo prazer versus esforço no processo de aprendizado. Sendo evidente a imaturidade que consistiria em procurar o prazer sem csforço, vale pensar, por outro lado, na incficácia de promover um esforço que tem de estar, a priori, desprovido de prazer. Talvez. seja o momento de pensar em educar com esforço a partir do prazer. Islo quer dizer que se pode aprender $e$ ao mesmo tempo faxê-lo com prazer, divertindo-se. A dificuldade nāo é garantia de eficácia no aprendizado - nem na vida -, e o prazer, se decorre da motivação clara c continuada, impulsiona a nāo poupar os esforços necessários para superar as dificuldades, que, nesse ponto, sc configuram como elemento acidental, secundário. Uma perspectiva muito próxima, por analogia, à postura diante da vida quancio se tem claro um senlito pora viver, experimentando-se a conhecida sentençn de Nietzsche: "Quando se tem um porquê na vida, qualquer como se torna suportável"20.

Educar, pois, levando em conta o prazer, a tendência do que é desejado. Caberia perguntar como agir quando o desejo de prazer parece dificultar mais do que ajudar no processo de aprendizado. Os clássicos, educadores por excelência, nos oferecem uma importante ajuda. P'latāo afirma que a finalidade da educação é ensinar a desejar o que se deve desejar. Aristóteles também fala de educar o descjo. lestamos aqui perante um novo desafio: educar o desejo, mostrar os caminhos para que o desejo se eduque. Uma perspectiva de educaçāo do paladar afetivo, que ensina a gostar do que é bom. Ensinar a sabedoria verdadeira; em palavras de Bernardo de Claraval: "Sábio é aquele a quem as cuisas sabem como elas são".

liste processo requer maturalmente tato, habilidade, evilar precipitações, promovendo um aprendizado que respeite, de algum modo, o ritmo quase fisiológico da emotividade. Nào se pode obrigar ninguém a sentir o que não sente. l'odese simplesmente mostrar, c o tempo - e a reflexão sobre as emoçōes - se encarregará de aprimorar o paladar afetivo. Tal processo foi denominado, com sabor clássico, "educaçāo sentimental"2!. Esta seria a funçāo do educador, afinal um promotor da cultura, que deve despertar o desejo por aprender, contagiar o entusiasmo por conhecer e conseguir que o estudante invisfa o melhor de seus impulsus para procurar, também por meios próprios, o conhecimento que the será de utilidade. Esta é a funçào do educador e da universidade, que deve ser uma "projęção institucional do estudante"22.

É fácil deduzir a fłexibilidade e criatividade que se esperam do educador e que devem ter seu reflexo nas metudologias educacionais empregadas. Um educador trabalha com pessoas, nāo apenas com idéias e, portanto, nāo pode partir unicamente das idéias preestabclecidas, mas também deve se adaptar às reaçōes suscitadas no interlocutor. A flexibilidade 
que a metodologia deve carregar consigo se apresenta como um verdadeiro desafio para o educador. "Se a nova geração não conseguc converter as imagens em pensamento" - comenta Ferrés, convergindo na cultura do espetáculo $=$, e porque o educador antes não conseguiu converter o pensa-

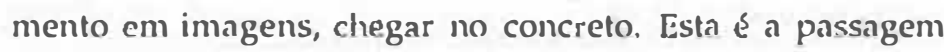
obrigatória a que se deve recorrer nos dias de hoje para atingir 0 aluno".

Pode-se concluir com facilidade como nesta cultura do espetáculo, onde a imagem, as emoçìes e a intuição são privilegiadas por serem a sintonia natural na qual o estudante se move, o narrativo - a história concreta - cncontra-sc também potencializado sobre o discursivo. Tudo se faz histsria, excmplo, que se tradu\% em imagem. Uma imagem que pode ser rápida, imediata, momentânea, como o próprio contexto cultural que está habituado ao dinamismo, às mudanças bruscas, a uma atitude de zapping c de clip, em palavras de Ferrés. Um terreno fértil que convida à utilização do cinema como recurso educacional.

\section{O CINEMA COMO RECURSO EDUCACIONAL}

Com acerto e profundidade filosúfica, Julián Marias's tece um amplo comentário sobre a funçào educadora do cinema no século 20, fazcndo notar que o cinema aumenta as possibilidades do concreto, das vivências, que em cada pessoa se encontram reduridas a um pequeno repertório de experiéncias reais. $\mathrm{O}$ cinema aumenta a possibilidade de ver e de ouvir. Aristótcles dizia que os homens desejam as percepçñes, c, sem dúvida, o cinema multiplicou notavelmente esta possibilidade. É como um aumento de opçóes para a catarse emotiva. Anota Marias num parágrafo sumamente expressivo:

O cinemn nos descobre os recnutos do mumdo. Por meio dele reparamos nos detalhes. O cinema nos faz sair da abstraçño em que o homem culto costumava viver. (...) Apresenta a vida 110 seu concreto. $O$ amor deixa de ser uma palaurn e se turna visivel elli ollhos, gestos, vozes, veijos. O cansafo i a figuru, precisa, de uma criança dormindo num canto, a figura deitada un cama, a mantira como se deixam cair os braf̧os quando os vence a fudiga ou o desânimo. Aprendemos, com o cinema, a ver os homens e as mulheres uns suas posturas renis, nos seus gestos, vivos, "nho posando para 1 mi quadro de histórin ou um retralu. Sabemos como é distinto comer, sentar-se, dar imma bojetada, cravar pumhal, e abraf̧ar, $e$ ir embora depois que se obteve um!n negaf̧no a um pedido. (...) Quando falamos da penu de morle, mio queremos dizer um urligo do código, quatro liuhas de prosa adminisIrativa, mas as costas de "Im homem contra o paredón, ns eletrodos que buscam a pele mua, uma corda que upurtn o pescofo, o mesmo ane outras vezes foi objeto de caricias ou levou um colar de pérolas. A guerra não é umma retúrica ou noticia: é lama, insônia, riso, alegria de uma carta, euforia da comsida, umma mīo que munce voltari, a explosios que se anumcin como a evidencia do irremediaivel. Tudo isto e muito mais vill e ouviu o homem do nossu século pela primeira vez ma história. O jue ajuer dizer que o seu umundo e sua vida, gruçns ao cinema, sho inteiramente distintens do que sempre formm, e isto é justamente o que tpuer dizer educaçōo.

A convivência virtual - nas palavras desse autor - tornasc enorme, amplifica-sc e acontece de fato como experiência, o que, humanamente, na sua realidade corpórea, nunca teria sido possivel. Os sentimentos, as paixĩes, já imaginados c descritos na literatura, encontram no cinema sua versīo sensorial: conseguimos vê-los, ouvi-los, compreendê-los através das palavras pronunciadas. Fica assim enfatizada a função do cinema como um recurso de educaçào em atitudes humanas, e tudo o que cada atitude encerra: valores, virtudes, limitaçōes, formas, enfim, o espectro amplíssimo dos modos de ser humano. Ainda aponta Marias:

faz lempo que vewho definindo o cinema como "um dedo que aponta', que estabelce conexżes entre as coisas, que as interpreła se'm necessidade de dizer nada, que zai além da simples justaposição fisica das coisas para unir o que estri junto e presente 11 um vida (...) Estas concxủes dảo relevo an dramatismo que é a condiçĩo humuna. Este és o antidoto do ut ilitarismo, da homogeneielade a que tantos e'stimulos conduzem hoje mossn minido.

Uma homogeneidade que poderiamos denominar globalização em linguagem moderna, interpretando o sentir do autor, que conclui:

Assusto pensor o que serin o mundo alual, submetido a toutas pressỏes manipulndoras, se nno existisse o cinemu, que lembra no homem o mais verdadeiro da sun realidade, o seu ncontecer, $e$ nssim o obriga a ver, imnginar, projetar, ter presen te a ilimitadn diversidade da vida e a necessidade de escolher entre as Irajelorias abertas. Não é excessivo dizer que o cinemn ई o instrmmento por excelêncin da educnfã̃o sentimental no nusso tempo.

As experiências vivenciadas através do cinema ${ }^{23.24 .25}$ no contexto educacional com os alunos apontam resultados alentadores, que descortinam novas perspectivas na formaçĩo midica. Assim, para citar as mais importantes, criam-se oportunidade e espaço para um diálogo amplo, multitemático, de 
questōes que ocupam e preocupam, de fato, o estudante e que nem sempre encontram espaço formal acadêmico para serem abordadas. O educador surge como um facilitador do diálogo entre os alunos, expondo temas relativos ao ser humano e à vida, geralmente partindo das cenas apresentadas nos filmes, onde os estudantes, habitualmente, projetam seu mundo pessoal. O diálogo entre os alunos é enriquecedor e meio de crescimento pessoal, quando se aprende a ouvir as opiniões dos outros, existindo realmente uma troca de perspectivas.

O cinema é uma forma sensível do narrativo. Uma forma rápida, de impacto, na qual se contam histórias. Sendo a cultura do estudante adaptada a estes parâmetros, a experiência com o cinema provoca o relato de histórias. Na discussão, os alunos complementam seus pontos de vista com histórias pessoais: reais, de sua própria vida, ou fictícias, extraídas de outra fonte ou mesmo de outro filme. Cria-se deste modo um cenário propício, com trânsito livre para contar histórias, sendo o contato com o cinema o fator desencadeante. O contar histórias tem um desdobramento de caráter muito mais íntimo e pessoal: nas vivências com o cinema, os estudantes se espelham nos filmes. O espectador tem a oportunidade de viver o conflito como expressão metafórica de seus próprios conflitos, aos quais se transporta durante a experiência. Esta dimensão absolutamente pessoal enriquecerá as discussões posteriores à projeção, também como recurso de partilhar o vivenciado - não apenas as cenas observadas, mas os conflitos vividos - para clarificar, e em busca de ajuda. A experiência suscita sentimentos, emoção; na discussão, os alunos procuram entender e esclarecer esses sentimentos.

Um parâmetro de qualidade, que de algum modo confirma a utilidade deste recurso na educação médica, é a facilidade com que os alunos transportam para o campo médico as vivências com o cinema, em produções que carecem de temática especificamente médica. Não é em absoluto necessário explicar por que as questões humanas que protagonizam os debates e discussões teriam importância na formação dos futuros médicos, pois é algo admitido e vivenciado explicitamente pelos alunos. A cultura da imagem é essencialmente metafórica, e os alunos demonstram habilidade e rapidez para extrair das analogias as conseqüências educacionais implícitas, particularmente as relacionadas com a promoção de atitudes e valores.

A facilidade de traduzir a vivência cinematográfica em objetivos práticos reais que orientem as atitudes cotidianas faz com que o aluno incorpore a linguagem cinematográfica como um meio de comunicação entre os alunos e mesmo entre os alunos e o professor. Esta linguagem servirá para exprimir-se e dar-se a conhecer, em processo inverso ao des- crito na incorporação das metáforas: se o aluno transporta o vivenciado no cinema para a sua vida pessoal e se espelha nos filmes, também utilizará as cenas dos filmes para revelar seu universo interior. Será um recurso de expressão rápido, emotivo, pontual, concreto, narrativo: totalmente inserido na cultura da imagem e dos sentimentos na qual o estudante está contextualmente imerso. As frases de impacto, trechos de diálogos, situações contempladas nos filmes convertem-se em linguagem para se comunicar e também para se dar a conhecer. O cinema empresta ao aluno sua força comunicativa e através dele consegue exprimir realidades que com palavras não conseguiria tornar transparentes. A cultura discursiva $\mathrm{e}$ lógica, com a qual o aluno tem pouca familiaridade, é substituída pela cultura da imagem e da emoção, não apenas para conhecer, mas para se exprimir e mostrar sua realidade vital como pessoa.

Os benefícios educativos da linguagem cinematográfica como meio de comunicação ultrapassam o espaço curricular acadêmico e se prolongam no aprendizado do cotidiano. As vivências com o cinema, que proporcionam ao estudante um meio de comunicação rápido e acorde com seu contexto cultural, fazem com que a reflexão se prolongue além do espaço dedicado às discussões. Deste modo, as vivências cinematográficas criam no aluno uma atitude reflexiva que, por estar ancorada num idioma de fácil recordação, atrelado a situações concretas e perpassado de atitudes perante a vida, o faz continuar no processo de reflexão durante o seu cotidiano. Assim, a história de vida, a frase de impacto, a situaçăo vivenciada voltam à tona fora do espaço convencional de educação - fora da sala de aula ou da discussão programada - e incitam o aluno a continuar pensando, refletindo, numa permanência que é inquietude por aprender. É o que os alunos intitulam textualmente como "detonadores", isto é, provocadores de reflexão.

Em seu conjunto, a experiência com o cinema traz advertências importantes para o educador. Com o emprego desta metodologia pode-se comprovar o impacto que uma educação centrada na gratificação que a experiência proporciona, $\mathrm{e}$ não apenas no acúmulo de dados, traz para o estudante. $\mathrm{A}$ gratificação motiva, cria vontade de aprender, e o aprendizado acontece durante a experiência e consegue se prolongar depois, nas realidades do dia-a-dia. Uma vontade de aprender que permanece e desemboca naturalmente na reflexão, conseguindo-se assim a integração desejada: partir da emoção, da imagem, do concreto, para naturalmente -fisiologicamente e seguindo o ritmo do próprio aluno - chegar à construção de conceitos, à fundamentação lógica do aprendizado. O livre trânsito das emoções durante a vivência, amplificado pela dis- 
cussão posterior, faz com que o aluno, quando se defronta fora da aula com situações ou mensagens similares, acrescente reflexão à emoção' ${ }^{19}$.

Esta metodologia pode ser usada em vários cenários educacionais, sempre que os professores tenham familiaridade $e$ gosto pelas humanidades e priorizem o aprendizado centrado no aluno, isto é, saibam estar atentos ao processo de aprendizado, à provocação nos alunos da vontade de refletir e aprender, mais do que ao conteúdo programático a ser cumprido a qualquer custo. Trabalhar emoções requer do docente disposição, criatividade e vontade de aprender junto com os alunos. O professor que atua como facilitador é, sem dúvida, um elemento determinante do sucesso desta metodologia.

Mas nem tudo corre por conta do carisma do educador. Existem cenários educacionais onde esta metodologia é perfeitamente adequada aos objetivos educacionais propostos. Assim, no caso da Medicina de Família como disciplina acadêmica ${ }^{26}$, que enfatiza a medicina centrada no paciente e năo na doença, promove a discussão em grupos e incorpora as humanidades de modo formal no seu currículo, o uso das artes e, em particular, do cinema para promover a reflexão é algo intrínseco e peculiar ${ }^{27}$. O presente trabalho recolhe também a experiência dos autores no uso do cinema para ensinar humanismo a estudantes de Medicina, como parte das atividades desenvolvidas pela Sociedade Brasileira de Medicina de Familia (Sobramfa), recolhidas em publicações e apresentadas em congressos internacionais ${ }^{28-31}$.

O cinema surge, assim, como ume metodologia inovadora que pode colaborar eficazmente na formação humanística do futuro médico. Um médico que não terá mais remédio que ser humanista se pretende estar à altura das responsabilidades que a sociedade lhe exige. Um médico que conseguirá no seu cotidiano ser humanista, porque vê o paciente como pessoa, considera seu entorno social e psicológico, tem sensibilidade, afeto e ética, e demonstra cordialidade com o enfermo 28-31. Um médico que sabe viver, na prática e no dia-a-dia, a ciência e a arte da medicina.

\section{APÊNDICE: EXEMPLIFICANDO A EDUCAÇÃO ATRAVÉS DO CINEMA}

\section{O que se pode obter com o cinema na educação?}

- Ensinar valores humanos, virtudes e atitudes;

- Promover a reflexão individual, trabalhá-la educacionalmente e fomentar atitudes, elementos essenciais na formação da pessoa;

- Criar uma linguagem de comunicação rápida e eficaz entre os estudantes e com o professor, que prolonga o aprendizado do dia-a-dia.

\section{Passos de uma metodologia}

- Utilizar cenas de filmes não médicos, selecionadas previamente e editadas em clipes de acordo com determinado tema;

- Fazer comentários simultâneos às cenas projetadas;

- Ao final da projeção, discutir as cenas com os participantes: o que viram, o que sentiram, o que foi despertado;

- Incentivar os participantes a montar seu próprio clipe com as cenas que sejam mais significativas para eles.

\section{A título de exemplo: cenas de filmes (clipes) com comentários}

\section{Idealismo}

Instinto - "O que você perdeu? Suas ilusões"

Tucker - "Não importa se são 50 ou 50 milhões. O que conta é o ideal, o sonho"

\section{Bioética}

Frankenstein - "Quem sou eu? Você alguma vez pensou nas conseqüências dos seus atos?"

\section{A dor e o sofrimento}

Terra das Sombras - "A dor é o megafone de Deus para acordar um mundo adormecido"

Fortalecer os princípios diante das dificuldades

O Show de Trumam - "Aumente o vento... Ele continua atado ao barco"

Realismo e perspectivas de vida

Adorável Professor - "A vida é o que te acontece enquanto estás ocupado fazendo planos"

O que é o amor: generosidade versus egoísmo

As Filhas de Marvin - "Sou feliz porque tive muito amor para dar en minha vida"

Amizade e nobreza: ajudar com criatividade

Perfume de Mulher - "Dê-me um motivo para não me matar. Danças tango e diriges uma Ferrari como ninguém"

Suporte para as dúvidas vitais

Casablanca - "Eu não sei mais o que é certo... Você terá que pensar por nós dois"

Todo ser humano é único

Amistad - "A criança escrava nasce livre, sem correntes" 
Liderança

Tempos de Glória - "Se vocês não vão receber o pagamento, ninguém receberá... Para as batalhas é preciso mais do que descanso. É preciso caráter, pujança de coração"

Responsabilidade e compromisso

O Resgate do Soldado Ryan - "James, faça por merecer! Eu vivi minha vida da melhor maneira que pude. Espero que diante dos seus olhos tenha sido suficiente e tentha merecido o que todos vocês fizeram por mim"

\section{REFERÊNCIAS}

1. Monasterio F. Planteamiento del Humanismo Médico. Humanismo e Medicina. II Encuentro Cultural de la Sociedad Española de Médicos Escritores; 1992, Murcia (SP): Previsión Sanitária Nacional \& Colégio Oficial de Médicos. 1992.

2. Marañón G. La medicina y nuestro tiempo. Madrid (SP): Espasa Calpe; 1954.

3. Gallian DMC. A (re)humanização da medicina. Psiquiatria na Pratica Médica 2000; 33 (2): 5-8.

4. González Blasco P. O médico de família, hoje. São Paulo: Sobramfa; 1997.

5. Robb D. Ciência, humanismo e medicina. Rassegna 1985; 3: $21-32$

6. Calman $\mathrm{KC}$. Literature in the education of the doctor. Lancet. 1997; 350: 1622-24.

7. Calman KC, Downye RS, Duthie M. "Literature and medicine: a short course for medical students". Med Educ 1988; 22: 265-9.

8. Downie RS, Hendry RA, Macnaughton RJ, Smith BH. The humanizing medicine: a special study module. Med Educ $1997 ; 4: 276-80$

9. Maheux B, Delorme P, Beaudry J. Humanism in medical education: a study of educational needs perceived by trainees o three Canadian schools. Acad Med 1990; 65 (1) 41-5.

10. Shapiro J. Literature and the Arts in Medical Education. Fam Med 2000; 32 (3): 157-8.

11. Mathiasen H, Alpert JS. Only connect: musing on the relationship between literature and medicine. Fam Med 2001; 33 (5): 349-51.

12. Whitman N. A poet confronts his own mortality: what a poet can teach medical students and teacher. Fam Med $2000 ; 32(10): 673-4$.
13. Moreto G, Roncoletta AF, Pinheiro TR, González Blasco P. Teaching humanities through opera: leading medical students to reflective attitudes. Conference Program. Symposium. WONCA $17^{\text {th }}$ World Conference of Family Doctors-Orlando, Florida- Oct. 2004.

14. González Blasco P, Levites MR, Roncoletta AFT, Moreto G, Freeman J. Arts and Humanism in medical education to promote family medicine. Conference Program. Symposium. WONCA $17^{\text {th }}$ World Conference of Family Doctors- Orlando, Florida- Oct. 2004.

15. González Blasco P. Literature and movies for Medical Students. Fam Med. 2001; 33 (6): 426-8.

16. González Blasco P, Levites MR, Albini RR. O valor dos recursos humanísticos na educação médica: literatura e cinema na formação acadêmica. Rev Videtur. 1999; (8): 31-40.

17. Ruiz Retegui A. Pulchrum: reflexiones sobre la Belleza desde la Antropologia Cristiana. Madrid: Rialp; 1999.

18. Macintyre A. Trás la virtud. Barcelona: Crítica; 1987.

19. Ferrés J. Educar en una cultura del espectáculo. Barcelona: Paidós; 2000.

20. Frankl VE. Psicoterapia e sentido da vida. São Paulo: Quadrante; 1973

21. Marías J. La educación sentimental. Madrid: Alianza Editorial; 1992.

22. Ortega y Gasset J. Missão da Universidade. Rio de Janeiro: EdUERJ; 1999.

23. González Blasco P, Roncoletta AFT, Moreto G, Levites MR, Azevedo RS. Recursos Literários e Cinematográficos na Educação Médica. Anais do II Congresso Paulista de Educação Médica; Maio, São Paulo; 2000.

24. González Blasco P, Levites MR, Moreto G, Roncoletta AFT, Azevezdo RS The value of humanistic resources in medical education: literature and movies for medical students. 16 th World Congress of Family Doctors. Conference Program. Poster Session. May 2001; Durban, South Africa.

25. González Blasco P, Gallian DMC, Roncoletta AFT, Moreto G. Cinema para o estudante de medicina: um recurso afetivo/efetivo na educação médica. XL Congresso da ABEM. Maio-Ago 2002, Fortaleza, 2002. In: Revista Brasileira de Educação Médica. maio-ago. 2002; 26 (supl.1):70.

26. Roncoletta AFT, Moreto G, Levites MR, Janaudis MA, González Blasco P, Leoto RF. Princípios da Medicina de Família. São Paulo: Sobramfa; 2003.

27. González Blasco P. Medicina de Família \& Cinema: Recursos Humanísticos na Educação Médica. São Paulo: Casa do Psicólogo; 2002. 
28. González Blasco P, Moreto G, Roncoletta AFT, Leoto RF, Valle TR. Humanities through cinema: using movie clips to teach family medicine core values and address students emotions. Conference Program. Workshop. WONCA $17^{\text {th }}$ World Conference of Family Doctors- Orlando, FloridaOct. 2004.

29. González Blasco P, Roncoletta AFT, Moreto G, Gallian DMC, Freeman J. Teaching humanities through Movies: A Cinema Course for Medical Students. Seminar. 36th Annual Spring Conference of the Society of Teachers of Family Medicine Atlanta, Georgia, USA September 2003.

30. Levites MR, Pinheiro TR, Janaudis MA, González Blasco P. The value of humanistic resources in medical education: literature and movies for medical students. Conference
Program. Symposium. WONCA $17^{\text {th }}$ World Conference of Family Doctors- Orlando, Florida- Oct. 2004.

31. Levites MR, Valle TR, Golfan C, Janaudis MA, González Blasco P. The use of cinema to teach humanism in family medicine. Conference Program. Symposium. WONCA $17^{\text {th }}$ World Conference of Family Doctors- Orlando, Florida-Oct. 2004.

\section{Agradecimentos}

Contribuíram de forma indispensável para a elaboração deste artigo Marcelo R. Levites e Marco Aurélio Janaudis, médicos da Sobramfa, a quem gostaríamos de agradecer explicitamente. 